Article

\title{
Energy Return on Energy Invested (EROI) for the Electrical Heating of Methane Hydrate Reservoirs
}

\section{Roberto Cesare Callarotti}

Universidad del Turabo, 00778 Gurabo, Puerto Rico; E-Mail: robercallarotti@gmail.com

Received: 10 June 2011; in revised form: 1 August 2011 / Accepted: 5 August 2011 /

Published: 7 November 2011

\begin{abstract}
We model the low frequency electrical heating of submarine methane hydrate deposits located at depths between 1000 and $1500 \mathrm{~m}$, and determine the energy return on energy invested (EROI) for this process. By means of the enthalpy method, we calculate the time-dependent heating of these deposits under applied electrical power supplied to a cylindrical heater located at the center of the reservoir and at variable depths. The conversion of the produced water to steam is avoided by limiting the heater temperature. We calculate the volume of methane hydrate that will melt and the energy equivalent of the gas thus generated. The partial energy efficiency of this heating process is obtained as the ratio of the gas equivalent energy to the applied electrical energy. We obtain EROI values in the range of 4 to 5, depending on the location of the heater. If the methane gas is used to generate the electrical energy required in the heating (in processes with a $33 \%$ efficiency), the effective EROI of the process falls in the range of $4 / 3$ to $5 / 3$.
\end{abstract}

Keywords: EROI; methane hydrates; electrical heating; electromagnetic heating; moving boundary problems; enthalpy method

\section{Introduction}

Methane hydrates are water-methane compounds which are present under the proper temperature and pressure conditions either at the bottom of the sea close to continental shelves or in the subsoil [1-3]. They are important due to the very large amounts of methane they contain [4,5]. By 1999 Japan had already started very significant efforts to produce gas from land and oceanic deposits [6].

In view of the importance of avoiding methane hydrate plugs in oil production pipes, we extended our work on the electromagnetic heating of petroleum [7] to the microwave heating of methane hydrate plugs $[8,9]$ and to the low frequency $(50-60 \mathrm{~Hz})$ heating of reservoirs. Here we present 
additional results related to this low frequency heating, with special attention given to the energy return on energy invested (EROI) of the process.

In Figure 1 we indicate the stability conditions for a methane hydrate deposit situated at the bottom of the sea, at depths between 1000 and $1500 \mathrm{~m}$. In Figure 2 we show the geometry used in the model: (a) the reservoir is assumed to have cylindrical symmetry; (b) a cylindrical electrical heater is located at the center of the reservoir (at different depths); (c) a water temperature of $2{ }^{\circ} \mathrm{C}$ is assumed at the top of the reservoir; (d) the temperature along the sides of the deposit (and at the bottom) is determined by the geothermal gradient of $40^{\circ} \mathrm{C} / \mathrm{Km}$. The results of the model are obtained in relation to a cylindrical coordinate system $(\mathrm{R}, \mathrm{Z})$ whose origin is located at the center of the top of the reservoir.

When the heater is turned on, different regions of the reservoir will heat up and dissociate when they reach the melting temperature of $22{ }^{\circ} \mathrm{C}$, thus liberating methane gas. The key objective of this paper is the determination of the ratio of the energy equivalent of the methane given off in the molten regions, to the electrical energy supplied. We feel that knowing this partial efficiency factor is essential for establishing the theoretical feasibility of electrical heating schemes of methane hydrate (MH).

In Section 2 we determine the temperature variations in the hydrate region due to the applied power distribution. In Section 3 we present the results for the energy efficiencies obtained for different heaters and heater locations in the reservoir. Finally, we present conclusions derived from the present work with recommendations for future extensions.

Figure 1. Conditions for the existence of methane hydrate deposits in porous sediments below the sea surface: shaded region indicate methane hydrate $(\mathrm{MH})$ deposits. The dotted curve line indicates the phase transition between the solid and the (gas + liquid) regions. The continuous lines indicate the temperature gradients in the seabed and in the water.

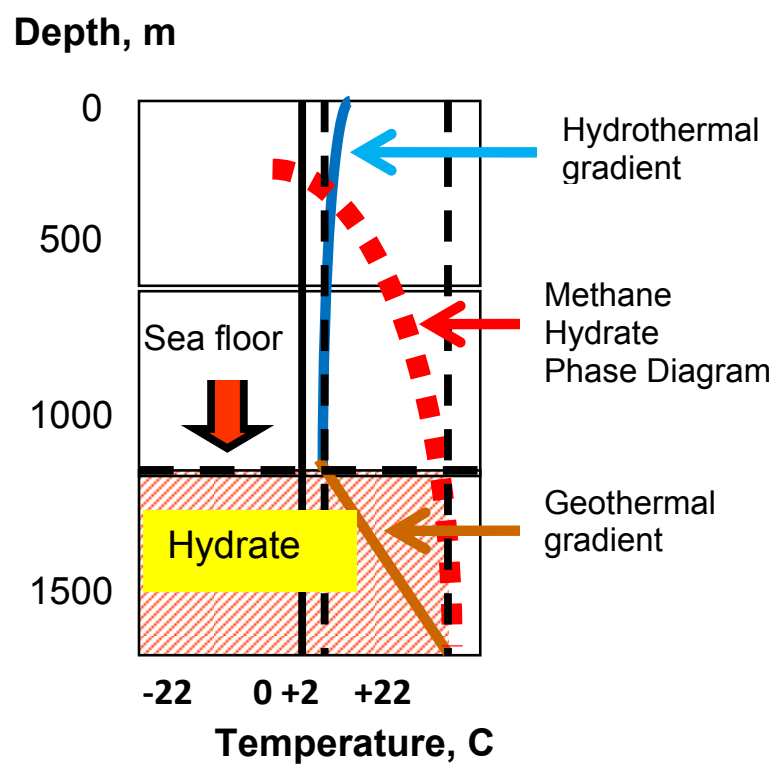


Figure 2. The system: A surface low frequency $(50-60 \mathrm{~Hz})$ electrical source is connected by cables (located inside cross-section of a circular pipe) to an electrical heater located inside a methane hydrate reservoir. Rh is the heater radius, Lh the length of the heater, Dh the depth of the heater, Dmh the diameter of the reservoir, and Lmh the reservoir length.

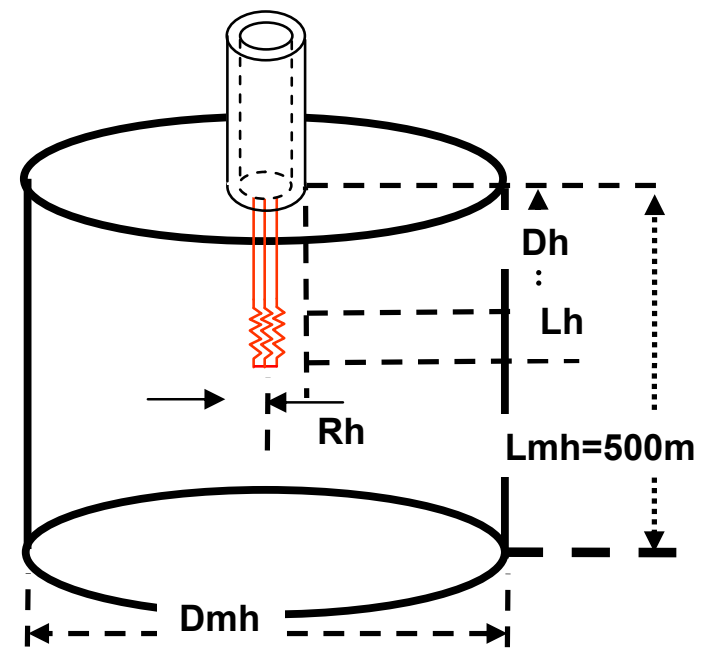

\section{Temperature Distribution in the MH Deposits}

The heater shown in Figure 2 is supplied by low frequency $(50-60 \mathrm{~Hz})$ electrical energy from a surface power source, transferred to the bottom via conventional cables located inside a production pipe - in the same scheme used for the high voltage $(2000 \mathrm{~V})$ supply to submersible pumps used in heavy oil production.

The heater pipe is assumed to have a radius of $0.1524 \mathrm{~m}$ (6 inches), and is located at the center of the cylindrical $\mathrm{MH}$ reservoir. In the calculations, the methane region is considered to have up to 400 times the radius of the heater $(6.1 \mathrm{~m})$ and a thickness of $500 \mathrm{~m}$. As the hydrate melts, the surface separating the solid from the liquid plus gas region will move outwardly from the power source. This moving boundary heat transfer problem (a Stefan problem) can be solved numerically by several special heat transfer methods outlined by Chun-Pyo [10]. The details of the numerical solution for our geometry are given in reference [9].

The values that we used for the different material properties $[11,12]$ are:

$\mathrm{MH}$ : latent heat $=438540$ joules $/ \mathrm{kg}$

$\mathrm{MH}$ specific heat $=2108$ joules $/(\mathrm{kg} \mathrm{K})$

$\mathrm{MH}$ density $=913 \mathrm{~kg} /\left(\mathrm{m}^{3}\right)$

$\mathrm{MH}$ thermal conductivity $=0.5$ watts $/(\mathrm{m} . \mathrm{K})$

Water specific heat $=4187$ joules $/(\mathrm{kg} . \mathrm{K})$

Water density $=1000 \mathrm{~kg} /\left(\mathrm{m}^{3}\right)$

Water thermal conductivity $=0.58$ watts $/(\mathrm{m} . \mathrm{K})$

Copper specific heat $=385$ joules $/(\mathrm{kg} . \mathrm{K})$

Copper density $=8920 \mathrm{~kg} /\left(\mathrm{m}^{3}\right)$

Copper thermal conductivity $=401$ watts $/(\mathrm{m} . \mathrm{K})$ 
By turning the heater off, the temperature of the heater is maintained at a temperature below a selected maximum temperature $\left(\operatorname{Tmax}=200{ }^{\circ} \mathrm{C}\right)$ in order to avoid temperatures that would vaporize the water produced from the $\mathrm{MH}$ dissociation. Thus the only gas produced is the methane. At depths of $1000 \mathrm{~m}$ the pressure is close to $10^{7}$ pascals corresponding to a temperature of evaporation of some $300{ }^{\circ} \mathrm{C}$.

Figure 3 and Figure 4 show how the temperature varies inside the reservoir as time progresses.

Figure 3. Temperature inside the reservoir $T(R, Z=25 \mathrm{~m}, \mathrm{t})$ vs. $\mathrm{R}$ at different times. Melting temperature $=22^{\circ} \mathrm{C}$. A $30 \mathrm{KW}$ heater is located on top of reservoir (radius $=0.1524 \mathrm{~m}$, length $=75 \mathrm{~m}, \operatorname{Tmax}=200^{\circ} \mathrm{C}$ ).

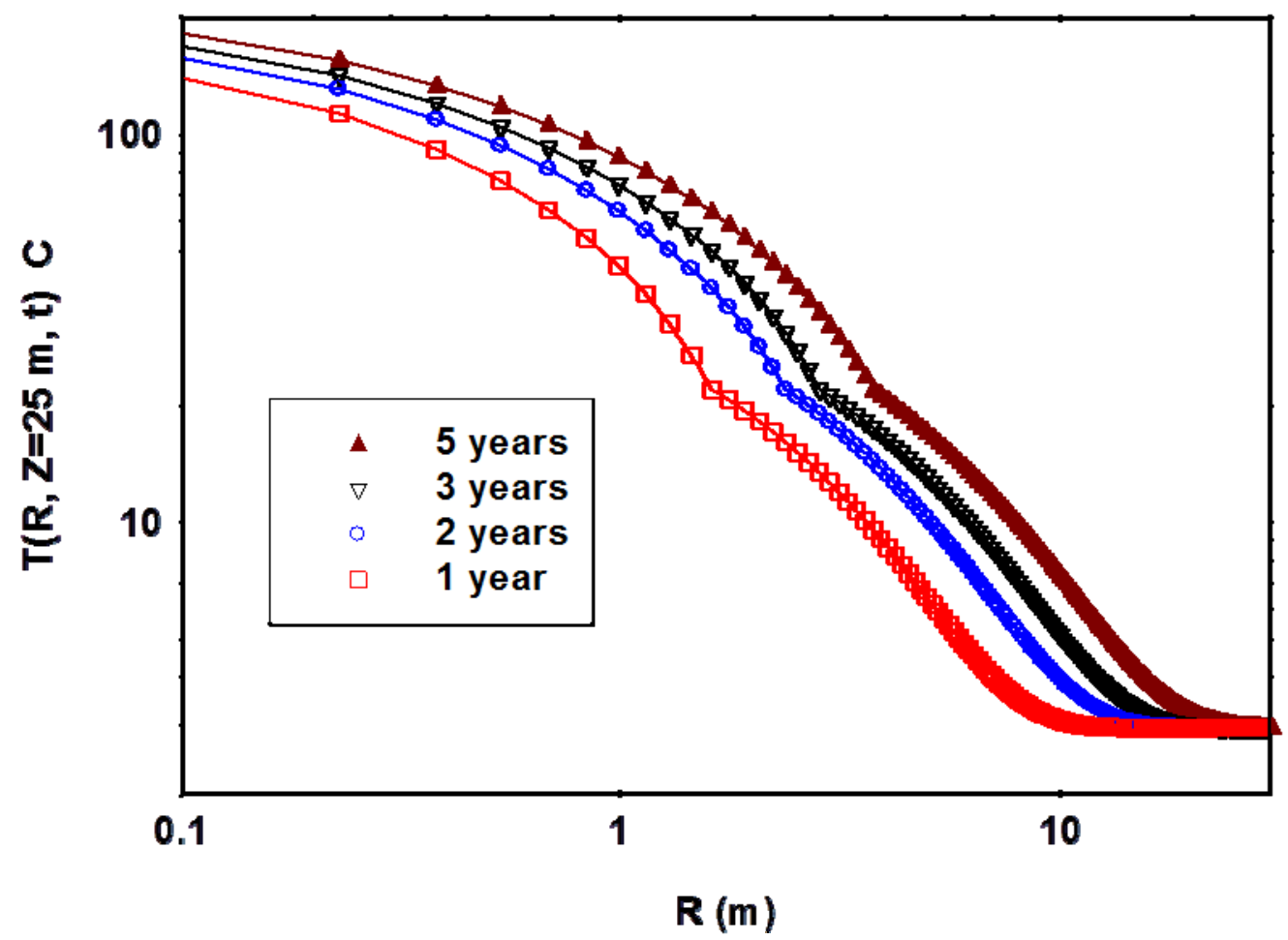

\section{Energy Efficiencies at Different Input Power Levels}

In this section we present the results of the equivalent energy corresponding to the volumes of methane hydrate that melt at $22{ }^{\circ} \mathrm{C}$ in different parts of the reservoir. This equivalent energy is taken to be of the order of $6.1 \times 10^{9}$ joules for each cubic meter of methane hydrate. We determine this value in the following manner:

(1) One cubic meter of methane hydrate yields 160-170 cubic meters of methane at standard temperature and pressure (STP $0{ }^{\circ} \mathrm{C}$ and $\left.1 \mathrm{~atm}\right)$

(2) Measurements of the heat of combustion of methane [13] yield a value of $8.906 \times 10^{5}$ joules/mol corresponding to $3.868 \times 10^{7}$ joules $/ \mathrm{m}^{3}$ of methane. This value closely agrees with an energy content of 1000 BTU per cubic foot, well in the range of the 500-1000 BTU per cubic foot reported in the literature for natural gas [14].

(3) Thus 1 cubic meter of methane hydrate producing $160 \mathrm{~m}^{3}$ of methane gas yields an equivalent energy of $6.1 \times 10^{9}$ joules. 
Figure 4. Temperature inside the reservoir $\mathrm{T}(\mathrm{R}, \mathrm{Z}, \mathrm{t}=1$ year) $v s . \mathrm{Z}$ at different $\mathrm{R}$ values. Melting temperature $=22{ }^{\circ} \mathrm{C}$. A $30 \mathrm{KW}$ heater is located on top of reservoir (radius $=0.1524 \mathrm{~m}$, length $=75 \mathrm{~m}$, Tmax $=200{ }^{\circ} \mathrm{C}$.

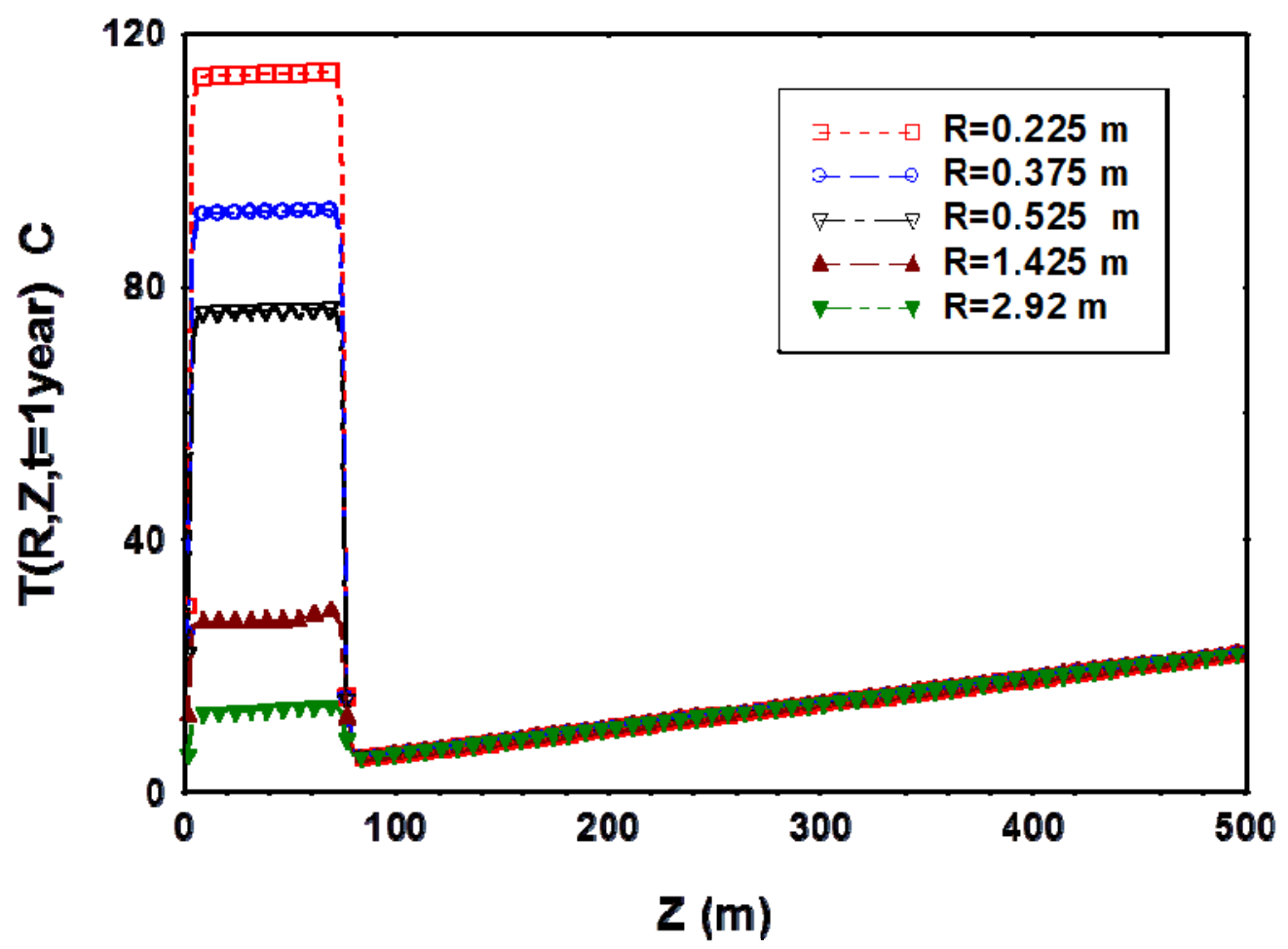

In the following figures we show the results given by our heat transfer model for the energy efficiency of the process. We define this EROI as the ratio of the equivalent energy of the methane separated (in those reservoir sections where the temperature exceeds $22{ }^{\circ} \mathrm{C}$ ), divided by the electrical energy applied.

As time increases, the applied electrical energy will increase while the energy gain decreases, as the available MH volume decreases. When all the MH deposit has melted, no further energy associated to the methane gas will be available, and the energy efficiency will be zero. This is evidenced in Figure 5 where the results over a 50 year time span are shown.

The results show that a heater located at the top is less efficient than a heater located deeper in the reservoir. This is because of the $2{ }^{\circ} \mathrm{C}$ boundary condition which is maintained at the top of the reservoir.

Figure 6 shows the results for a five year heating span, with an applied power of $30 \mathrm{KW}$, with $100 \mathrm{~m}$ long heaters located at the top $(\mathrm{EROI} \approx 3.7$ ), midway down the reservoir (EROI $\approx 4.6$ ), and down at the bottom of the reservoir $(\mathrm{EROI} \approx 5.4)$.

Important information about the heating process of methane hydrate reservoirs can be obtained by examining the plots of the time averaged energy input and the energy gain $v s$. the length of different heaters located at the top of the reservoir, for different levels of applied electrical power. The results are shown in Figures 7 and 8. 
Figure 5. Energy gain over a 50 year period, for a $30 \mathrm{KW}, 100 \mathrm{~m}$ long heater located at the top of the reservoir and at a depth of 200 to $300 \mathrm{~m}$.

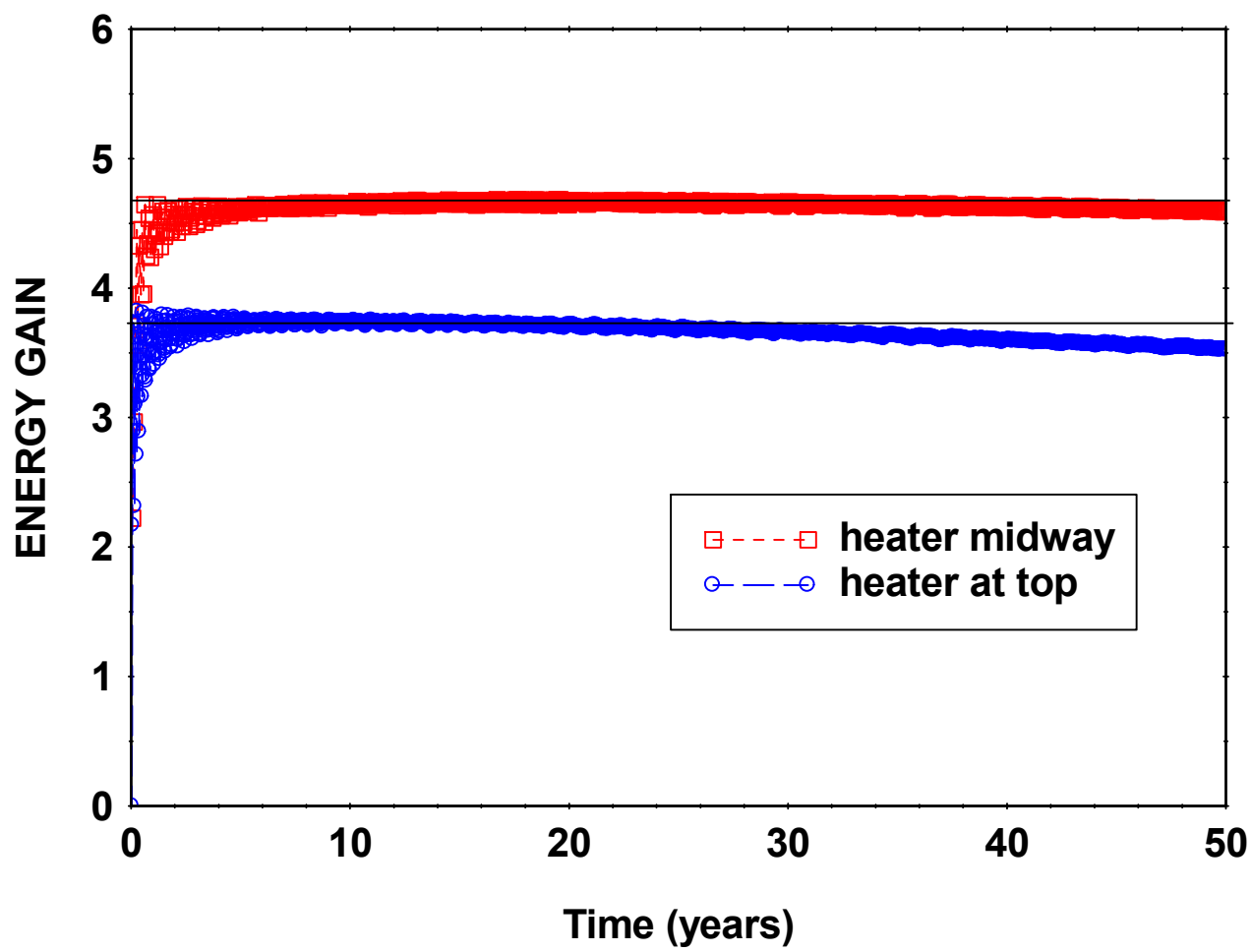

Figure 6. Energy gain over a 5 year period, for a $30 \mathrm{Kw}, 100 \mathrm{~m}$ long heater located at the bottom of the reservoir, at a depth between 200 and $300 \mathrm{~m}$, and at the top.

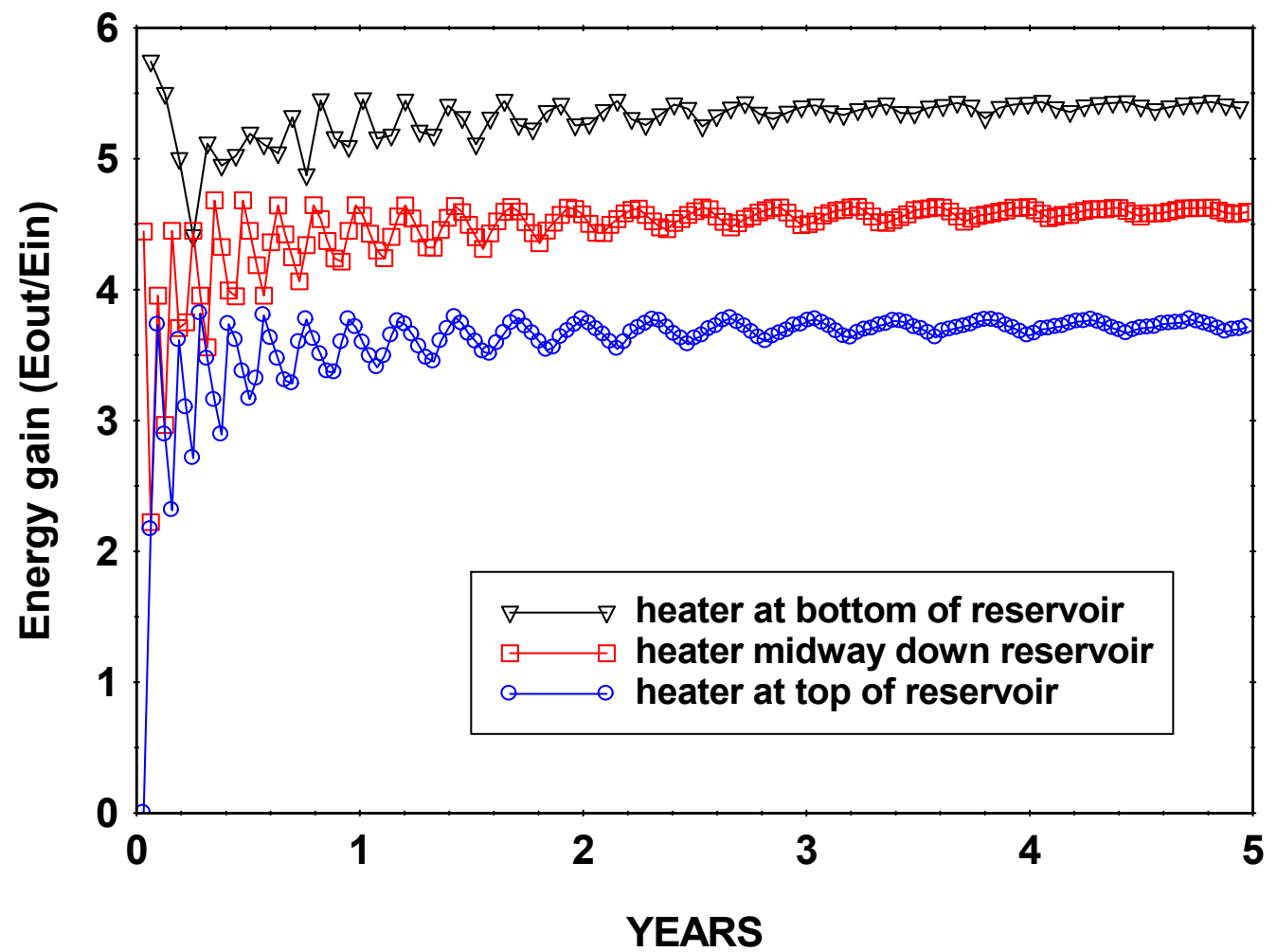


Figure 7 shows that the time averaged input energy will tend to a constant when the different heaters are always ON (thus dissipating maximum power). Initially they are ON and OFF (as controlled by the temperature limiting system), but as their length increases the power density will decrease and they will be $\mathrm{ON}$ all the time.

Figure 7. Time averaged energy input over a 5 year period $v s$. heater length for different heater powers. The heaters are located at the top of the reservoir (radius $=0.1524 \mathrm{~m}$, $\left.\operatorname{Tmax}=200{ }^{\circ} \mathrm{C}\right)$.

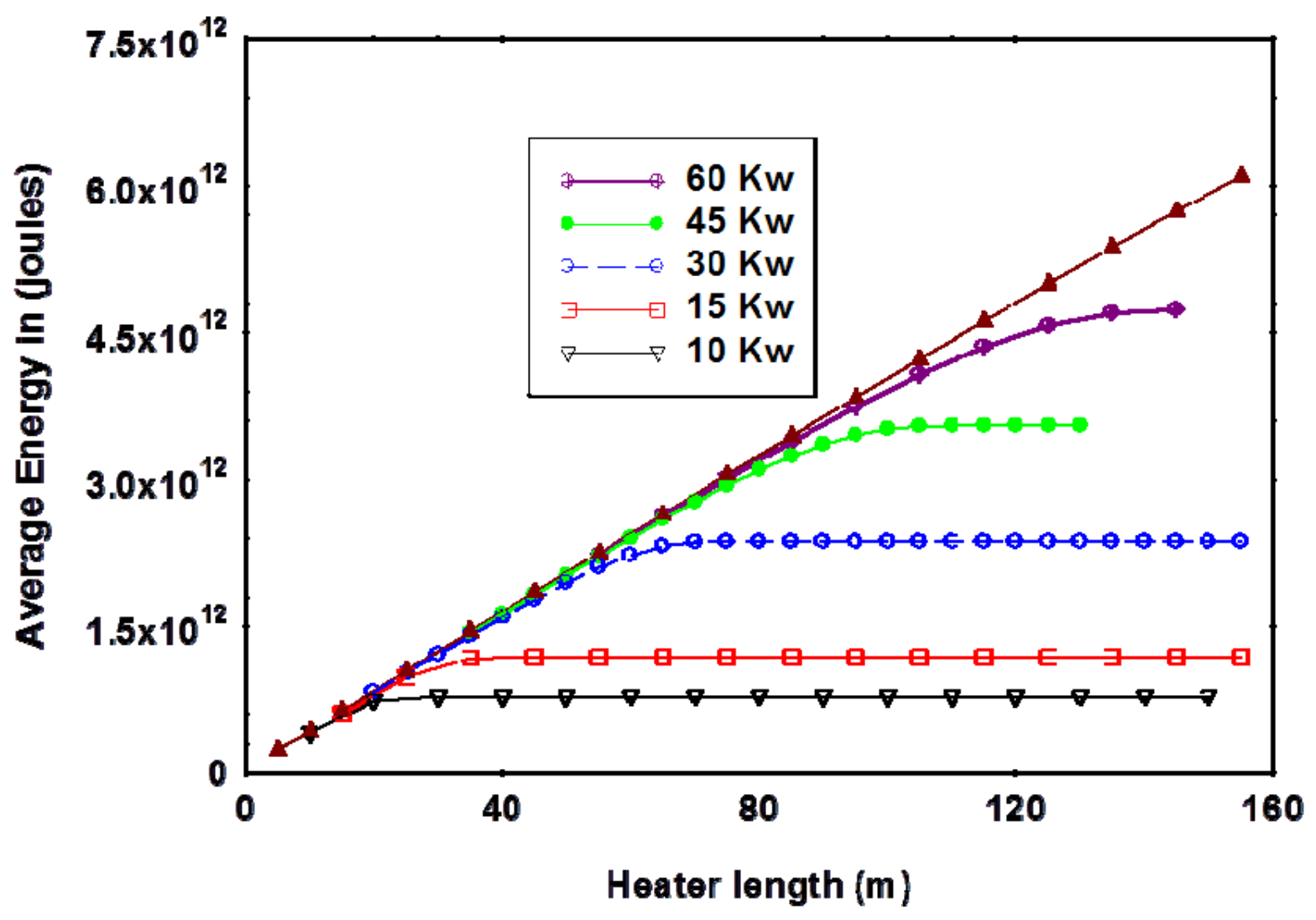

This effect is also shown in Figure 8 where the energy gain is plotted as a function of heater length. The figure shows that at a certain length, a maximum point is reached in energy gain, and then this energy gain decreases as the power density in the heaters is reduced when their volume increases.

Figure 8 shows the level corresponding to an energy gain of 3. Only energy gains above this level will yield a positive energy gain for $50-60 \mathrm{~Hz}$ electrical heating. This is the case when electrical energy is produced by conventional thermal plants with efficiency of the order of $33-34 \%$. 
Figure 8. Energy gain (Energy out/Energy in) over a 5 year period vs. heater length for different heater powers. The heaters are located at the top of the reservoir (radius $=0.1524$ $\left.\mathrm{m}, \operatorname{Tmax}=200^{\circ} \mathrm{C}\right)$

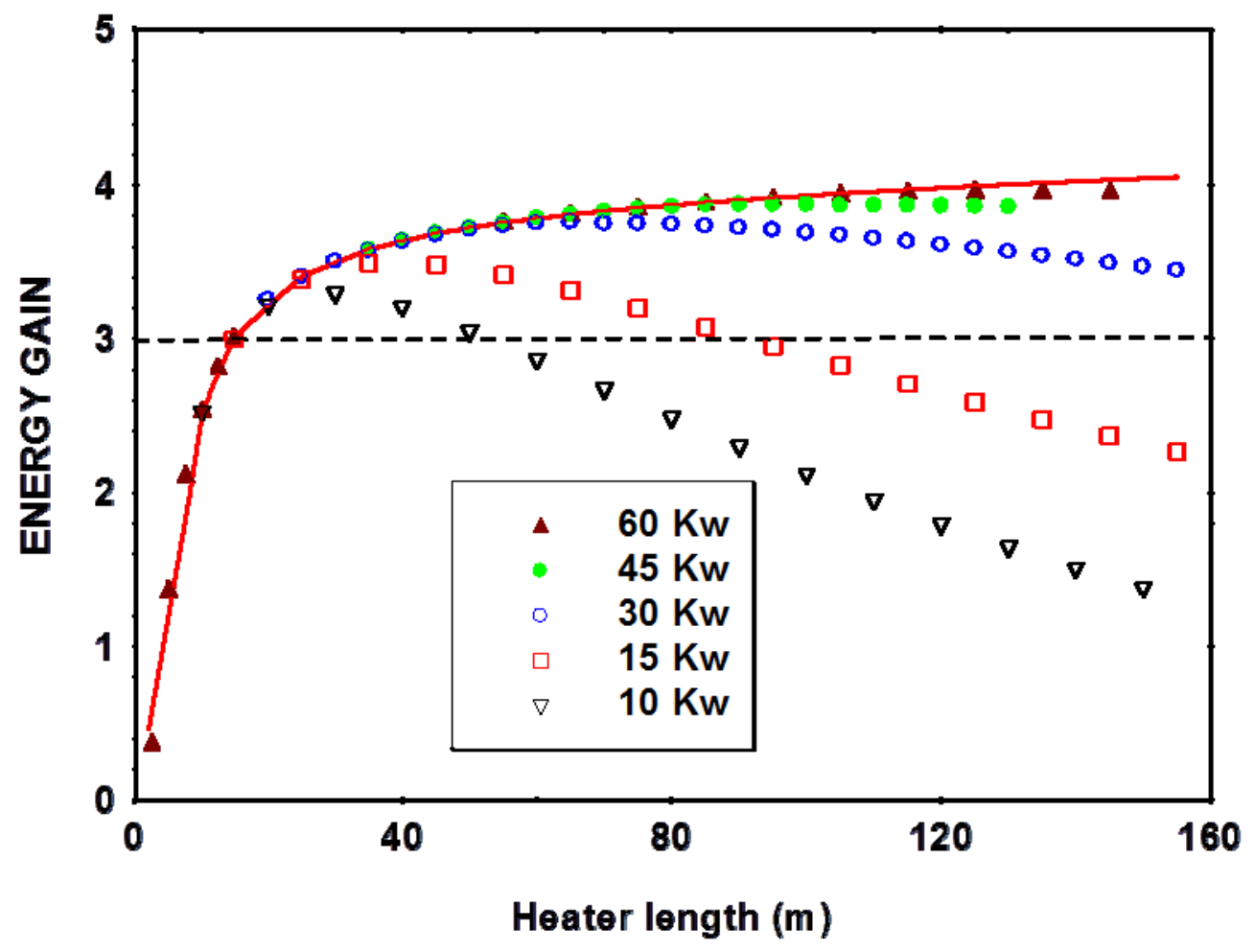

\section{Conclusions}

We have determined the response of seabed methane hydrate deposits under electrical low frequency heating. The losses associated with the cables from the surface to the heaters have not been considered. For heaters with three phase voltages of the order of 2000 volts, one can easily show that the energy loss along a cable is similar to that in cables used for submersible pumps of an order of $1-2 \%$, for cable lengths of one kilometer.

For heaters located at the top of the $\mathrm{MH}$ reservoirs the maximum EROI (energy return on energy invested) is of the order of $(3.7 / 3)=1.24$ (see Figure 6). This is the EROI value for the case when only the electrical energy is considered in the calculation.

If one were to consider the energy required for the construction of the heaters, the pipes, and the pipe and the installation process, the total EROI would be even less. Electrical heating using microwaves is out of the question as the efficiency of conversion from $60 \mathrm{~Hz}$ to microwaves is of the order of $50 \%$.

Ideally, for maximum net energy balance, the electrical heaters used for the production of methane from methane hydrate deposits should be energized with electrical power generated by hydroelectricity, where the efficiency of generation is of the order of $80-85 \%$.

An interesting heating scheme, using hot water produced in the heater exchanger of a floating electrical power plant located close to the $\mathrm{MH}$ reservoir, was presented by T. Yamakawa et al. in reference [15]. This is the scheme proposed for the production of gas from the submarine deposits 
located in the Eastern Nankai trough off the coast of Japan. It would certainly be interesting to determine the EROI for this process.

The results obtained in this paper indicate that methane hydrate plugs in oil producing pipelines could be conveniently eliminated with the insertion of electrical heaters. Problems with MH plugs can be analyzed and solved along the lines of the present paper using different temperature boundary conditions. For these problems the EROI concept is not pertinent.

\section{References and Notes}

1. Makogon Y.F. Hydrates of Natural Gas; PennWell Publishing Company: Tulsa, OK, USA, 1981.

2. Sloan E.D. Clathrate Hydrates of Natural Gases; Marcel Dekker Inc.: New York, NY, USA, 1998.

3. Carroll, J. Natural gas Hydrates, 2nd ed.; Elsevier: Oxford, UK, 2009.

4. Kvenvolden, K.A. Gas hydrates as a potential energy resource: A review of their methane content. In The Future of Energy Gases; USGS Professional Paper 1570. USGS: Reston, VA, USA, 1993; pp. 555-561.

5. Demirbas, A. Biohydrogen: For Future Engine Fuel Demands; Springer-Verlag: London, UK, 2009.

6. Arata, N., Sukizaka S., Awashima Y., Okada Y., and Ogisako E., Overview of the R\&D Program For An Environmental Impact Assessment Of Hydrate Exploitation in Japan. In Proceedings of OCEANS'08 MTS/IEEE conference, Quebec, Canada, September 2008, IEEE Press.

7. Callarotti, R.C., Electromagnetic heating of oil, in SPE Handbook of Petroleum Engineering Vol. 6; Chapter 12, Lake, L., Ed., Society of Petroleum Engineers: Houston, TX, USA, 2007; Volume 6, pp. 567-609.

8. Callarotti, R.C., Methane Hydrates As An Energy Source, In Proceedings of the International Annual Conference Interdisciplinary Approaches to Sustainability, CIEMADEeS Second International Annual Conference, Gurabo, Puerto Rico, 3-5 November 2006, retrieved from http://ciemades.org/gurabo06_eng.html

9. Callarotti, R.C. Energy Efficiency In The Electrical heating Of Methane Hydrate Reservoirs. SPE paper 137585. In Proceedings of the Canadian Unconventional Resources and International Petroleum Conference, CURIPC 10, Calgary, Alberta, Canada, 19-21 October 2010; Society of Petroleum Engineers: Houston, TX, USA

10. Chun-Pyo, H. Computer Modeling of Heat and Fluid Flow in Materials Processing; Institute of physics printing: Bristol, UK, 2004.

11. Gupta, A. Lachance, J.; Sloan, E.D.; Koh, C.A. Measurements of methane hydrate heat of dissociation using high pressure differential scanning calorimetry. Chem. Eng. Sci. 2008, 63, 5848-5853.

12. Waite, S.F. Stern, L.A.; Kirby, S.H.; Winters, W.J.; Mason, D.H. Simultaneous determination of thermal conductivity, thermal diffusivity and specific heat in sI methane hydrate. Geophys. J. Int. 2007, 169, 767-774.

13. Dale, A.; Lythall, C.; Aucott, J.; Sayer, C. High precision calorimetry to determine the enthalpy of combustion of methane. Thermochim. Acta 2002, 382, 47-54.

14. Speight, J.G. Synthetic Fuel Handbook; McGraw Hill: New York, NY, USA, 2008. 
15. Yamakawa, T. , Ono S., Iwamoto A., Sugai Y., and Sasaki K.; A Gas Production System From Methane Hydrate Layers By Hot Water Injection And BHP Control With Radial Horizontal Wells. SPE paper 137801. In Proceedings of the Canadian Unconventional Resources and International Petroleum Conference, CURIPC 10, Calgary, Alberta, Canada, 19-21 October 2010; Society of Petroleum Engineers: Houston, TX, USA

(C) 2011 by the authors; licensee MDPI, Basel, Switzerland. This article is an open access article distributed under the terms and conditions of the Creative Commons Attribution license (http://creativecommons.org/licenses/by/3.0/). 